\title{
Distinct role of the CYP4F2 polymorphisms in determining the risk of HAPE among Chinese Han population
}

\author{
Yanli Zhao \\ Qinghai University \\ Haiyuan Wang \\ QInghai Red Cross Hospital \\ Guifen Gan \\ Affiliated Hospital of Qinghai University \\ Rong Wang \\ Qinghai University \\ Qifu Long \\ Qinghai University \\ Derui Zhu \\ Qinghai University \\ Guoping Shen \\ Qinghai University \\ Lining Si ( $\sim$ liningsi21@163.com) \\ Affiliated Hospital of Qinghai University
}

\section{Research}

Keywords: CYP4F2, Genetics polymorphisms, High altitude pulmonary edema, Case-control study

Posted Date: March 3rd, 2020

DOI: https://doi.org/10.21203/rs.3.rs-15767/v1

License: (c) (i) This work is licensed under a Creative Commons Attribution 4.0 International License. Read Full License 


\section{Abstract}

Background: CYP4F2 is potentially associated with High altitude pulmonary edema (HAPE) risk by regulating inflammatory mediator leukotriene B4 and arachidonic acid. However, the role of CYP4F2 in HAPE susceptibility remains unknown. For the first time, we conducted a case-control study to assess the potential association of CYP4F2 gene variants (rs3093193, rs12459936, rs3093144 and rs3093110) with HAPE susceptibility in Chinese Han population.

Methods: The study included $238 \mathrm{BC}$ patients and 230 healthy controls from northwest China. The polymorphisms selected in CYP4F2 gene were genotyped by Agena MassARRAY system. Odds ratios (ORs), 95\% confidence intervals (95\% Cls), and $P$ values were used to evaluate the relationship between the two.

Results: In the allele model and genotype model of the overall analysis, rs3093193 was shown to reduce the risk of HAPE $(P \otimes 0.05)$, while rs12459936 increased susceptibility to HAPE (Pष0.05). Age stratified analysis revealed that rs3093193 and rs12459936 were correlated with HAPE risk at age $>32$ years $(P \otimes 0.05)$, and rs3093193 and rs3093110 were correlated with the HAPE risk at age $\leq 32$ years $(P \otimes 0.05)$. Gender stratification analysis found that rs3093193, rs12459936 and rs3093110 were all related to HAPE risk in males $(P \otimes 0.05)$. Haplotype analysis illuminated that GCCG and CTC could increase HAPE risk at age $\leq 32$ years and males, respectively $(P \otimes 0.05)$.

Conclusions: Our research confirmed that CYP4F2 genes polymorphisms were implicated in HAPE susceptibility in Chinese Han population.

\section{Introduction}

High altitude pulmonary edema (HAPE) is a hypoxia-induced, non-cardiogenic pulmonary edema that may develop in otherwise healthy individuals when first quickly ascended and exposed to altitude above $2500 \mathrm{~m}$ (1). It is characterized by excessive pulmonary arterial hypertension, which leads to pulmonary capillary stress failure and caused a high permeability type of life- threatening pulmonary edema (2, 3 ), with common symptoms of cough, dyspnea, chest tightness, and fatigue (4). HAPE occurs and develops rapidly, and it can develop into a coma or even life-threatening in a short period of time if left untreated (5). However, the exact pathogenesis of HAPE remains is still not yet clear.

As we all know, Hypoxia induction is one of the principal element in the occurrence of HAPE (6). More often, hypoxia can also induce inflammation (7). The inflammatory mediator is a vital regulator of increased vascular permeability and vasodilatation (8). Vascular permeability increased, vasoconstriction of diastolic imbalance is a crucial mechanism of acute high altitude disease. In an earlier research to assess the cellular and biochemical components of bronchoalveolar fluid in high-altitude pulmonary edema (HAPE), they performed bronchoalveolar lavage in three climbers with HAPE in a research facility at $4400 \mathrm{~m}$ on Mount McKinley. They eventually found that HAPE fluid contained a large number of alveolar macrophages and detectable amounts of inflammatory factors such as leukotriene-B4 and other lipoxygenase products of arachidonic acid metabolism $(9,10)$.

CYP4F2 (a member of 4 subfamily F2 of the cytochrome P450 family) is a member of the cytochrome P450 enzyme superfamily. Gilroy et al. stated that the expression of CYP4F2, CYP4F3, and CYP4A family enzymes is increased during inflammation (11). Additionally, CYP4F2encoded enzymes starts the process of inactivating and degrading leukotriene B4, a potent Mediator of inflammation (12). What is more, CYP4F2 related pathway also includes arachidonic acid metabolism, which can be metabolize arachidonic acid to 20-hydroxyeicosatetraenoic acid (20-HETE) (13). Arachidonic acid is also an important inflammatory cytokines, and its metabolic network is the core of the inflammatory metabolic network (13). CYP4F2-derived 20-HETE is known to have the characteristics of prehypertension and angiogenesis promotion (14). Therefore, we propose a reasonable hypothesis that the pathogenesis of HAPE is related to CYP4F2.

Single nucleotide polymorphisms (SNPs) have been proved to play a crucial role in the occurrence of HAPE. Many SNPs of inflammatory cytokines or genes associated with inflammation have been identified to be strongly correlated with susceptibility to pulmonary edema, for example, NR3C1(15), IL-6 (8), IL1R2 (16). To our knowledge, there are no previous studies have investigated the association of risk of HAPE and CYP4F2 polymorphisms. Hence, we perform a hospital-based case-control study to explore the correlation of the 4 tag SNPs in $C Y P 4 F 2$ at allele, genotype, and haplotype interface with HAPE susceptibility among Chinese Han women.

\section{Materials And Methods}

\section{Participates statement}

HAPE patients treated at the Department of Oncology, the Affiliated Hospital of Xizang Minzu University (Xi'an, China) were enrolled as cases. The diagnosis of HAPE patients was dependent on standard criteria (Hultgren and Marticoremna, 1978), including cough, dyspnea, cyanosis at rest, and imagological examination like X-ray radiograph, computed tomography (CT) of the patient chest or magnetic resonance imaging. All the HAPE patients eventually show that chest radiographic troves of infiltrates consistent with pulmonary edema. Healthy individuals who had a checkup at the hospital during the same period of time were recruited as controls. Controls were unrelated to each other and had no HAPE or 
related diseases after exposure to high altitude $(4000 \mathrm{~m})$ within 7 days. Each subject we recruited in present study was healthy people without any previous history of cancers, cardiopulmonary and infectious diseases or any other genetic diseases. Controls were matched to cases based on age ( \pm 5 years). Finally, 238 PE patients and 230 healthy individuals were enrolled in our study. All of the subjects were Han population from Northwest China and have no relation to each other.

\section{SNP selection and genotyping}

Peripheral blood samples of each subject was collected in tubes coated with ethylenediamine tetraacetic acid (EDTA). All samples were stored at $-80^{\circ} \mathrm{C}$, after centrifugation, whole blood cells were collected for further analysis (17). Then, Genomic DNA was extracted from whole blood using the GoldMag whole blood genomic DNA purification kit (GoldMag Co. Ltd., Xi an, China) following the manufacturer's guidelines, and DNA quantity was assessed utilizing the NanoDrop 2000C spectrophotometer (Thermo Scientific, Waltham, MA, USA). Four tag-SNPs (rs2881766, rs9383951, rs9340799 and rs3020449) in CYP4F2 were involved in our study based on 1000 Genomes Project (http://www.1000genomes.org/) and dbSNP (https: //www. ncbi.nlm.nih.gov/projects/SNP/) database. The minor allele frequency (MAF) value with > 0.05 in Chinese Han population was also applied to select candidate SNPs. Agena MassARRAY Assay Design 3.0 Software (San Diego, California, USA) was used to design the primers for amplification and single base extension. The corresponding primers of the selected SNPs in this study were listed in Supplementary Table S1. SNP genotyping was carried out by two laboratory personnel in a double-blinded manner using the Agena MassARRAY system (Agena, San Diego, CA, U.S.A.). Agena Bioscience TYPER version 4.0 software was used for data analysis. In order to verify the accuracy of genotyping, about $10 \%$ of the samples were randomly selected to repeat genotyping and the reproducibility was $100 \%$.

\section{Statistical analysis}

The differences in the basic characteristics between the cases and controls were compared using Student's t-test or $\chi 2$-test. Hardy Weinberg equilibrium (HWE) for selected SNPs among controls and the differences in genotypes distribution between cases and controls were examined by exact test and $\chi 2$-test, respectively. We evaluated the relationship of the four SNPs with HAPE risk based on five different genetic models (A and a are used to represent the major and the minor alleles, respectively): the allele model (a vs. A); the co-dominant model (homozygote model: aa vs. AA; heterozygote model: Aa vs. AA); the recessive model (aa vs. AA + Aa); the dominant model (AA vs. Aa + aa); and the log-additive model. Odds ratios (ORs) with $95 \%$ confidence intervals (Cls) were calculated by multivariate logistic regression, with adjustment for age and gender. Stratified analyses were also performed by gender and age to understand the relationship between each SNP and HAPE risk in different subgroups. SHEsis software (http://analysis2.bio-x.cn/myAnalysis.php) software was used for haplotype analysis. For each haplotype, its correlation with the risk of high-altitude pulmonary edema was also evaluated by using OR and $95 \% \mathrm{Cl}$ and $P$-values. The results were presented as ORs, $95 \% \mathrm{Cls}$ and $P$ values, and a two sided $P$-value $<0.05$ was considered statistically significant. All the statistical analyses were performed using the software SPSS software package (version 20.0; SPSS Inc., Chicago, IL, USA) for Windows (18).

\section{Results}

\section{The basic characteristics of study subjects}

A total of 468 subjects including 238 HAPE patients (220 males and 18 females) and 230 healthy individuals (213 males and 17 females) were enrolled in this study. The mean age and standard deviation of the cases and the controls were $32.35 \pm 10.78$ and $33.45 \pm 9.05$ years, respectively. As shown in Table 1, There was no significant difference between the case and control groups in regards to the distribution of gender and age $(P=1.000$ and 0.236 , respectively).

\section{Basic information and preliminary statistics of the selected SNPs}

The basic information of the four SNPs was presented in Table 2. We genotyped the four SNPs (rs3093193, rs12459936, rs3093144 and rs3093110) and the genotyping success rates of the four SNPs were $>95.0 \%$ among the HAPE cases and the controls. The genotype distribution of of all SNPs in the control groups were in accordance with Hardy-Weinberg Equilibrium (HWE) $(P>0.05)$. The differences in allele frequency between cases and controls were compared by Chi-squared test, and whether the $P$ value was less than 0.05 to assess the association with the risk of developing HAPE. The minor allele of each SNP as a risk factor was compared to the wild-type (major) allele. Statistical analysis showed that the allele frequency of rs3093193 was significantly different between the healthy control group and the HAPE patients, and rs3093193 was significantly correlated with the reduced risk of HAPE (OR $=0.70,95 \% \mathrm{Cl}=0.52-0.93, P=0.014)$. However, the other three SNPs (rs 12459936 , rs3093144 and rs3093110) were not significantly associated with HAPE risk in the allele model $(P=0.099, P=0.252$ and 0.050 , respectively).

\section{Associations between genotype frequencies and HAPE susceptibility}

Multiple inheritance models (dominant, recessive, additive, and codominant models) were applied for analyzing the association between each SNP and HAPE risk in Table 3. Among the four CYP4F2 polymorphisms, rs3093193 was found to reduce HAPE risk under dominant model (C/G$\mathrm{G} / \mathrm{G}$ vs. $\mathrm{GG}: \mathrm{OR}=0.66,95 \% \mathrm{Cl}=0.46-0.95, P=0.027)$ and log-additive model $(\mathrm{OR}=0.70,95 \% \mathrm{Cl}=0.52-0.94, P=0.017)$. As for polymorphism 
rs12459936, an increased risk of HAPE was found in the codominant model (C/T vs. C/C: OR $=2.08,95 \% \mathrm{Cl}=1.33-3.26, P=0.001)$ and the dominant model $(\mathrm{C} / \mathrm{T}-\mathrm{T} / \mathrm{T}$ vs. $\mathrm{C} / \mathrm{C}$ : OR $=1.88,95 \% \mathrm{Cl}=1.23-2.88, P=0.003)$. The other two SNPs (rs3093144 and rs3093110) were not related to HAPE susceptibility $(P>0.05)$.

\section{Stratification analysis of CYP4F2 polymorphisms and HAPE risk}

Stratified analysis regarding the impact of CYP4F2 polymorphisms on HAPE according to age are displayed in Table 4. The results indicated that rs3093193 was correlated with a decreased HAPE risk at age $\leq 32$ years under the allele model $(\mathrm{OR}=0.63,95 \% \mathrm{Cl}=0.42-0.95, P=0.028)$, codominant model (G/G vs. C/C: $\mathrm{OR}=0.28,95 \% \mathrm{Cl}=0.10-0.85, P=0.024)$ and recessive model $(\mathrm{G} / \mathrm{G}$ vs. $\mathrm{C} / \mathrm{C}-\mathrm{C} / \mathrm{G}: \mathrm{OR}=0.30,95 \% \mathrm{Cl}=0.10-$ $0.87, P=0.027)$. Rs12459936 was related to enhance HAPE risk at age $\leq 32$ years under the allele model $(\mathrm{OR}=0.63,95 \% \mathrm{Cl}=0.42-0.95, P=$ 0.028), codominant model (C/T vs. $\mathrm{C} / \mathrm{C}$ : $\mathrm{OR}=2.92,95 \% \mathrm{Cl}=1.52-5.63, P=0.001 ; \mathrm{T} / \mathrm{T}$ vs. $\mathrm{C} / \mathrm{C}: \mathrm{OR}=2.30,95 \% \mathrm{Cl}=1.10-4.83, P=0.027)$, dominant model (C/T-T/T vs. $\mathrm{C} / \mathrm{C}: \mathrm{OR}=2.69,95 \% \mathrm{Cl}=1.45-4.96, P=0.002)$ and log-additive model $(\mathrm{OR}=1.52,95 \% \mathrm{Cl}=1.05-2.19, P=0.026)$. Conversely, two loci (Rs3093193 and rs3093110) of BDNF gene were obversed decreased HAPE risk at age $>32$. Rs3093193 was correlated with a decreased HAPE risk at age $>32$ years under the codominant model $(\mathrm{C} / \mathrm{T}-\mathrm{T} / \mathrm{T}$ vs. $\mathrm{C} / \mathrm{C}: \mathrm{OR}=0.57,95 \% \mathrm{Cl}=0.33-0.99, P=0.046)$. Rs3093110 was associated with a decreased HAPE risk at age $>32$ years under the allele model $(\mathrm{OR}=0.63,95 \% \mathrm{Cl}=0.42-0.95, P=0.028)$, codominant model (A/G vs. A/A: OR $=0.42,95 \% \mathrm{Cl}=0.21-0.83, P=0.013)$, dominant model (A/G-G/G vs. A/A: $\mathrm{OR}=0.44,95 \% \mathrm{Cl}=0.23-0.86, P=0.016)$ and log-additive model $(\mathrm{OR}=0.52,95 \% \mathrm{Cl}=0.29-0.95, P=0.034)$.

Furthermore, we conducted another stratified analysis of gender adjusted for age as shown in Table 5. In males, rs3093193 was correlated with a decreased risk of HAPE in males under under the allele model (OR $=0.67,95 \% \mathrm{Cl}=0.50-0.91, P=0.010)$, codominant model $(\mathrm{C} / \mathrm{G}$ vs. $\mathrm{C} / \mathrm{C}$ : OR $=0.65,95 \% \mathrm{Cl}=0.44-0.97, P=0.036)$, dominant model $(\mathrm{C} / \mathrm{G}-\mathrm{G} / \mathrm{G}$ vs. $\mathrm{C} / \mathrm{C}$ : OR $=0.62,95 \% \mathrm{Cl}=0.42-0.91, P=0.015)$ and log-additive model $(\mathrm{OR}=0.67,95 \% \mathrm{Cl}=0.50-0.91, P=0.011)$. Rs 12459936 was related to improved risk of $\mathrm{LC}$ in the codominant model $(\mathrm{C} / \mathrm{T}$ vs. $\mathrm{C} / \mathrm{C}: \mathrm{OR}=2.12$, $95 \% \mathrm{Cl}=1.33-3.37, P=0.002)$ and dominant model (C/T-T/T vs. $\mathrm{C} / \mathrm{C}$ : OR $=1.94,95 \% \mathrm{Cl}=1.25-3.02, P=0.003)$. Rs3093110 was related to enhance HAPE risk in the allele model $(\mathrm{OR}=0.61,95 \% \mathrm{Cl}=0.40-0.94, P=0.026)$ and log-additive model $(\mathrm{OR}=0.63,95 \% \mathrm{Cl}=0.41-0.96, P=$ 0.034). No significant correlation between any genotypes among the SNPs rs3093144 and HAPE risk were observed.

\section{Associations between haplotype analyses and HAPE risk}

Finally, haplotype-based association and linkage disequilibrium (LD) study were conducted to show the association between CYP4F2 haplotype and risk of HAPE. Among the subpopulation (age $\leq 32$ years), three SNPs were found to exist in one LD block (rs3093193, rs12459936 and rs3093144) in CYP4F2 gene (Fig.1). The distributions of different haplotypes of CYP4F2 gene in both the patients of HAPE and controls, and its association with HAPE risk were presented in Table 6. The results showed that the haplotype CTC was found to prominently increase the risk of HAPE among age $\leq 32$ years under unconditional logistic regression analysis adjusted for age and gender $(\mathrm{OR}=1.52,95 \% \mathrm{Cl}=1.05-2.19, \mathrm{p}=$ 0.026). Other haplotypes did not display the correlativity.

\section{Discussion}

Researches have been revealed that HAPE may have an important pathogenesis of inflammation (19). A large amount of inflammatory cytokine genes and their single nucleotide polymorphisms have been identified to be associated with the risk of HAPE. However, the contribution of the SNPs in CYP4F2 gene to HAPE risk is remains unclear. Considering these, in this case-control study, allele, genotype and haplotype frequencies of four SNPs in the CYP4F2 gene between HAPE patients and healthy controls were compared and stratification analyses by age or gender were performed. In the overall, rs3093193 was shown to reduce the risk of HAPE, while rs 12459936 conferred the increased susceptibility to HAPE. Age stratified analysis revealed that rs3093193 and rs12459936 were correlated with the HAPE risk at age > 32 years, and rs3093193 and rs3093110 were correlated with the HAPE risk at age $\leq 32$ years. Gender stratification analysis found that rs3093193, rs12459936 and rs3093110 were all related to HAPE risk in males. Haplotype analysis illuminated that GCCG and CTC could increase HAPE risk at age $\leq 32$ years and males, respectively. As far as we know, this is the first study to evaluate the correlation of CYP4F2 SNPs with HAPE risk in Chinese Han population.

HAPE was identified as a non-inflammatory hemorrhagic pulmonary edema, which may be accompanied by secondary inflammation (9) Severe hypoxia induced by HAPE is prone to immunogenic changes and involvement in the development of HAPE, leading to significant changes in the prevalence of immune function during HAPE (20). Inflammatory markers of IL-1LIL-6冈leukotriene B4, arachidonic acid $\triangle \mathrm{CRP}$ and CCR5 are upregulated in response to high altitude, and hypoxia-induced inflammation at high altitude may contribute to the development of HAPE (21, 22). The CYP4F2 gene, known as a major member of the CYP450 subfamily, encodes o-hydroxylase. CYP4F2 gene is not only up-regulated in inflammatory response, but also participates in the metabolism of inflammatory factors such as leukotriene B4 and arachidonic acid. In humans, this gene is located on chromosome 19p13.12, and 225 SNPs for the human CYP4F2 gene listed in the National Center for Biotechnology Information SNP database Build 126 (http://www.ncbi.nlm.nih.gov/SNP). 
Furthermore, studies show that SNPs at many loci of the CYP4F2 gene are associated with various diseases, such as hypertension (23, 24), cerebral infarction (25) myocardial infarction (26-29), and metabolic syndrome (30). There are reports that some SNPs in CYP4F2 gene, such as rs3093105, rs3093135, rs3093200, rs1558139, and rs2108622, can cause an increase or decrease in o-hydroxylase activity, which results in altered levels of 20-HETE production (31). Studies have also shown that polymorphisms in CYP4F2, such as rs1558139 and rs2108622, can lead to an increased or decreased activity of the CYP4F2 gene (23). In the present case-control study, our results showed that two intron SNPs in the CYP4F2 gene (rs3093193 and rs12459936) were linked to the risk of HAPE, and three SNPs (rs3093193 and rs12459936) were related to the risk of HAPE in stratified analysis based on age and gender. This result demonstrated that CYP4F2 polymorphism are associated with susceptibility to LDH in Chinese Han population. Considering the established function of SNPs and their influence on gene expression, we speculated that SNPs may affect the occurrence risk of HAPE by changing the expression of CYP4F2 or its o-hydroxylase activity. However, the mechanisms still need more functional studies to testify. Moreover, we could not exclude the possibility that the deficiency of association in a certain group might be a consequence of the limited sample size.

Although in this study, we first investigated the association between CYP4F2 rs3093193, rs12459936 and rs3093110 polymorphisms and HAPE, there are still some potential limitations. Firstly, all participants were recruited from the identical hospitals, which may result in a poor representation. Secondly, the number of cases in our study was not large and our study population was all Chinese Han people, which can't preclude false-negative results and cannot be extrapolated to other populations. Finally, we only found CYP4F2 polymorphisms may be related to the development of HAPE, but the mechanisms have not been studied.

\section{Conclusion}

To summarize, our study provides the first for the association between CYP4F2 variant and HAPE risk in Chinese Han population, which may provide new data to facilitate earlier diagnosis and promote early prevention, and shed light on the new candidate genes and new ideas for the study. Further functional studies and a large number of well-designed studies are still needed to further clarify the effect of $C Y P 4 F 2$ polymorphism on HAPE.

\section{Abbreviation List}

\begin{tabular}{ll} 
HAPE & High altitude pulmonary edema \\
\hline SNP & Single nucleotide polymorphism \\
\hline HWE & Hardy-Weinberg equilibrium \\
\hline OR & Odds ratio \\
\hline $95 \% \mathrm{Cl}$ & $95 \%$ confidence intervals \\
\hline LD & Linkage disequilibrium \\
\hline MAF & Minor allele frequency
\end{tabular}

\section{Declarations}

\section{Ethics statement}

This research sought the consent of the Human Research Committee of the Affiliated Hospital of Qinghai University and conducted in accordance with the the approved guidelines. During the time of recruitment, the purpose of this study was well informed to the participants and written informed consent was obtained from each of them.

\section{Consent for publication}

Not applicable.

\section{Availability of data and meterial}

All relevant data are within the manuscript.

\section{Funding}

This research was supported by the National Natural Science Foundation of China (No. 81460284, No. 81460051, No. 31560039), Natural Science Foundation of Qinghai Provincial (No. 2014-ZJ-944Q), and Key point Research and Invention Program of Qinghai Provincial (No. 2019SF-121). 


\section{Competing interest}

Lining Si conceived and designed the experiments;

Haiyuan Wang and Guifen Gan: performed the experiments;

Rong Wang collected data;

Qifu Long analyzed the data;

Derui Zhu and Guoping Shen contributed reagents/materials/analysis tools;

Yanli Zhao wrote the paper.

\section{Acknowledgements}

We are grateful to the individuals for their participation in this study. We also thank the clinicians and hospital staff who contributed to the sample and data collection for this study. We would also like to thank all participants for this manuscript.

\section{References}

1. Mishra A, Ali Z, Vibhuti A, Kumar R, Alam P, Ram R, et al. CYBA and GSTP1 variants associate with oxidative stress under hypobaric hypoxia as observed in high-altitude pulmonary oedema. Clinical science (London, England : 1979). 2012;122:299-309.

2. Askew EW. Work at high altitude and oxidative stress: antioxidant nutrients. Toxicology. 2002;180:107-19.

3. Menon ND. HIGH-ALTITUDE PULMONARY EDEMA: A CLINICAL STUDY. The New England journal of medicine. 1965;273:66-73.

4. Scherrer U, Rexhaj E, Jayet PY, Allemann Y, Sartori C. New insights in the pathogenesis of high-altitude pulmonary edema. Progress in cardiovascular diseases. 2010;52:485-92.

5. Rong H, He X, Zhu L, Zhu X, Kang L, Wang L, et al. Association between regulator of telomere elongation helicase1 (RTEL1) gene and HAPE risk: A case-control study. Medicine. 2017;96:e8222.

6. Zhu L, Liu L, He X, Yan M, Du J, Yang H, et al. Association between genetic polymorphism of telomere-associated gene ACYP2 and the risk of HAPE among the Chinese Han population: A Case-control study. Medicine. 2017;96:e6504.

7. Eltzschig HK, Carmeliet P. Hypoxia and inflammation. The New England journal of medicine. 2011;364:656-65.

8. He X, Wang L, Zhu L, Yuan D, He Y, Jin T. A case-control study of the genetic polymorphism of IL6 and HAPE risk in a Chinese Han population. 2018;12:2419-25

9. Schoene RB, Hackett PH, Henderson WR, Sage EH, Chow M, Roach RC, et al. High-altitude pulmonary edema. Characteristics of lung lavage fluid. Jama. 1986;256:63-9.

10. Kubo K, Hanaoka M, Hayano T, Miyahara T, Hachiya T, Hayasaka M, et al. Inflammatory cytokines in BAL fluid and pulmonary hemodynamics in high-altitude pulmonary edema. Respiration physiology. 1998;111:301-10.

11. Gilroy DW, Edin ML. CYP450-derived oxylipins mediate inflammatory resolution. 2016;113:E3240-9.

12. Kikuta Y, Miyauchi Y, Kusunose E, Kusunose M. Expression and molecular cloning of human liver leukotriene B4 omega-hydroxylase (CYP4F2) gene. DNA and cell biology. 1999;18:723-30.

13. Aires V, Hichami A, Boulay G, Khan NA. Activation of TRPC6 calcium channels by diacylglycerol (DAG)-containing arachidonic acid: a comparative study with DAG-containing docosahexaenoic acid. Biochimie. 2007;89:926-37.

14. Cheng J, Edin ML, Hoopes SL, Li H, Bradbury JA, Graves JP, et al. Vascular characterization of mice with endothelial expression of cytochrome P450 4F2. FASEB journal : official publication of the Federation of American Societies for Experimental Biology. 2014;28:291531.

15. Yang Y, Du H, Li Y, Guan W, Tang F, Ga Q, et al. NR3C1 gene polymorphisms are associated with high-altitude pulmonary edema in Han Chinese. Journal of physiological anthropology. 2019;38:4.

16. Jin T, Zhu L, Bai M, He X, Wang L, Yuan D, et al. Association between the IL1R2 rs2072472 polymorphism and high-altitude pulmonary edema risk. 2019;7:e542.

17. Zhu Y, Jia H, Li J, Ren S, Huang Z, Li F, et al. Associations between Variants in BDNF/BDNFOS Gene and Lumbar Disc Herniation Risk among Han Chinese People. Scientific reports. 2018;8:12782.

18. Jin T, Yang H, Zhang J, Yunus Z, Sun Q, Geng T, et al. Polymorphisms and phenotypic analysis of cytochrome P450 $3 A 4$ in the Uygur population in northwest China. International journal of clinical and experimental pathology. 2015;8:7083-91. 
19. Ahsan A, Charu R, Pasha MA, Norboo T, Charu R, Afrin F, et al. eNOS allelic variants at the same locus associate with HAPE and adaptation. Thorax. 2004;59:1000-2.

20. Maggiorini M, Melot C, Pierre S, Pfeiffer F, Greve I, Sartori C, et al. High-altitude pulmonary edema is initially caused by an increase in capillary pressure. Circulation. 2001;103:2078-83.

21. Hartmann G, Tschop M, Fischer R, Bidlingmaier C, Riepl R, Tschop K, et al. High altitude increases circulating interleukin-6, interleukin-1 receptor antagonist and C-reactive protein. Cytokine. 2000;12:246-52.

22. Rosenberger P, Schwab JM, Mirakaj V, Masekowsky E, Mager A, Morote-Garcia JC, et al. Corrigendum: Hypoxia-inducible factor-dependent induction of netrin-1 dampens inflammation caused by hypoxia. Nature immunology. 2015;16:544.

23. Luo XH, Li GR, Li HY. Association of the CYP4F2 rs2108622 genetic polymorphism with hypertension: a meta-analysis. Genetics and molecular research : GMR. 2015;14:15133-9.

24. Ward NC, Tsai IJ, Barden A, van Bockxmeer FM, Puddey IB, Hodgson JM, et al. A single nucleotide polymorphism in the CYP4F2 but not CYP4A11 gene is associated with increased 20-HETE excretion and blood pressure. Hypertension (Dallas, Tex : 1979). 2008;51:1393-8.

25. Fan F, Ge Y, Lv W, Elliott MR, Muroya Y, Hirata T, et al. Molecular mechanisms and cell signaling of 20-hydroxyeicosatetraenoic acid in vascular pathophysiology. Frontiers in bioscience (Landmark edition). 2016;21:1427-63.

26. Fu Z, Nakayama T, Sato N, Izumi Y, Kasamaki Y, Shindo A, et al. A haplotype of the CYP4F2 gene is associated with cerebral infarction in Japanese men. American journal of hypertension. 2008;21:1216-23.

27. Yan HQ, Yuan Y, Zhang P, Huang Z, Chang L, Gui YK. CYP4F2 gene single nucleotide polymorphism is associated with ischemic stroke. Genetics and molecular research : GMR. 2015;14:659-64.

28. Fava C, Montagnana M, Almgren P, Rosberg L, Lippi G, Hedblad B, et al. The V433M variant of the CYP4F2 is associated with ischemic stroke in male Swedes beyond its effect on blood pressure. Hypertension (Dallas, Tex : 1979). 2008;52:373-80.

29. Deng S, Zhu G, Liu F, Zhang H, Qin X, Li L, et al. CYP4F2 gene V433M polymorphism is associated with ischemic stroke in the male Northern Chinese Han population. Progress in neuro-psychopharmacology \& biological psychiatry. 2010;34:664-8.

30. Tabur S, Oztuzcu S, Oguz E, Demiryurek S, Dagli H, Alasehirli B, et al. CYP gene expressions in obesity-associated metabolic syndrome. Obesity research \& clinical practice. 2016;10:719-23.

31. Stec DE, Roman RJ, Flasch A, Rieder MJ. Functional polymorphism in human CYP4F2 decreases 20-HETE production. Physiological genomics. 2007;30:74-81.

\section{Tables}

Table 1: Characteristics of HAPE patients and control participants

\begin{tabular}{lccc}
\hline \multicolumn{1}{c}{ Variables } & Case & Control & $P$ - value \\
\hline Total & 238 & 230 & \\
Age & & & $0.236^{\mathrm{a}}$ \\
\hline Age (mean \pm SD) & $32.35 \pm 10.78$ & $33.45 \pm 9.05$ & \\
$\quad \leq 32$ & $125(53 \%)$ & $115(50 \%)$ & \\
$>32$ & $113(47 \%)$ & $115(50 \%)$ & \\
Gender & & & $>0.05^{\mathrm{a}}$ \\
$\quad$ Male & $220(92 \%)$ & $213(93 \%)$ & \\
\hline Female & $18(8 \%)$ & $17(7 \%)$ & \\
\hline
\end{tabular}

\footnotetext{
$P^{a}$-value obtained from independent sample $t$-test;

$P^{\mathrm{b}}$-value obtained from Pearson's $\chi^{2}$ test;

$P \leq 0.05$ indicates statistical significance.
}

Table 2: Basic information and allele frequency of the selected SNPs in CYP4F2 gene 


\begin{tabular}{|c|c|c|c|c|c|c|c|c|c|c|c|}
\hline \multirow[t]{2}{*}{ SNP } & \multirow[t]{2}{*}{ Chr } & \multirow[t]{2}{*}{ Position } & \multirow[t]{2}{*}{ Gene(s) } & \multirow[t]{2}{*}{ Role } & \multirow[t]{2}{*}{ Alleles } & \multicolumn{2}{|c|}{$\begin{array}{c}\text { Frequency } \\
\text { (MAF) }\end{array}$} & \multirow[t]{2}{*}{$\begin{array}{c}P- \\
H W E\end{array}$} & \multirow[t]{2}{*}{$\begin{array}{c}\text { Call rate } \\
(\%)\end{array}$} & \multirow[t]{2}{*}{ OR (95\% CI) } & \multirow[t]{2}{*}{$\begin{array}{c}P- \\
\text { value }\end{array}$} \\
\hline & & & & & & Cases & Controls & & & & \\
\hline rs3093193 & 19 & 15881104 & CYP4F2 & intronic & $\mathrm{C} / \mathrm{G}$ & 112 & 141 & 1.000 & $100.0 \%$ & $\begin{array}{c}0.70(0.52- \\
0.93)\end{array}$ & $0.014^{*}$ \\
\hline rs12459936 & 19 & 15882231 & $C Y P 4 F 2$ & intronic & $\mathrm{C} / \mathrm{T}$ & 244 & 211 & 0.145 & $100.0 \%$ & $\begin{array}{c}1.24(0.96- \\
1.60)\end{array}$ & 0.099 \\
\hline rs3093144 & 19 & 15891487 & $C Y P 4 F 2$ & intronic & $\mathrm{A} / \mathrm{G}$ & 71 & 81 & 0.252 & $99.8 \%$ & $\begin{array}{l}0.82(0.58- \\
1.16)\end{array}$ & 0.252 \\
\hline rs3093110 & 19 & 15896974 & $C Y P 4 F 2$ & intronic & $\mathrm{C} / \mathrm{T}$ & 43 & 60 & 0.239 & $100.0 \%$ & $\begin{array}{c}0.66(0.44- \\
1.00)\end{array}$ & 0.050 \\
\hline
\end{tabular}

SNP: Single nucleotide polymorphism; HWE: Hardy-Weinberg equilibrium; OR: Odds ratio; 95\% Cl: 95\% confidence interval;

$P$-HWE obtained from Fisher's exact test;

$P$-value obtained from Wald test;

${ }^{*} P$-value $<0.05$ indicates statistical significance.

Table 3: Logistic regression analysis of the association between the single-nucleotide polymorphisms in CYP4F2 gene and HAPE risk

\begin{tabular}{|c|c|c|c|c|c|c|c|}
\hline \multirow[t]{2}{*}{ Model } & \multirow[t]{2}{*}{ Genotype } & \multirow[t]{2}{*}{ Control (n, \%) } & \multirow[t]{2}{*}{ Case (n, \%) } & \multicolumn{2}{|c|}{ Without adjustment } & \multicolumn{2}{|c|}{ With adjustment } \\
\hline & & & & OR (95\% CI) & $P$-value & OR (95\% CI) & $P$ - value \\
\hline rs3093193 & & 230 & 238 & & & & \\
\hline \multirow[t]{3}{*}{ Codominant } & $\mathrm{C} / \mathrm{C}$ & $110(47.8 \%)$ & 139 (58.4\%) & 1 & & 1 & \\
\hline & $\mathrm{C} / \mathrm{G}$ & 99 (43.0\%) & $86(36.1 \%)$ & $0.69(0.47-1.01)$ & 0.055 & $0.70(0.48-1.03)$ & 0.067 \\
\hline & G/G & $21(9.1 \%)$ & $13(5.5 \%)$ & $0.49(0.23-1.02)$ & 0.057 & $0.49(0.24-1.03)$ & 0.058 \\
\hline \multirow[t]{2}{*}{ Dominant } & $\mathrm{C} / \mathrm{C}$ & $110(47.8 \%)$ & 139 (58.4\%) & 1 & $0.022^{*}$ & 1 & $0.027^{*}$ \\
\hline & C/G-G/G & $120(42.2 \%)$ & $99(41.6 \%)$ & $0.65(0.45-0.94)$ & & $0.66(0.46-0.95)$ & \\
\hline \multirow[t]{2}{*}{ Recessive } & $\mathrm{C} / \mathrm{C}-\mathrm{C} / \mathrm{G}$ & 209 (90.9\%) & 225 (94.5\%) & 1 & 0.130 & 1 & 0.127 \\
\hline & G/G & $21(9.1 \%)$ & $13(5.5 \%)$ & $0.58(0.28-1.18)$ & & $0.57(0.28-1.17)$ & \\
\hline \multirow{3}{*}{$\begin{array}{c}\text { Log-additive } \\
\text { rs12459936 } \\
\text { Co-dominant }\end{array}$} & --- & --- & --- & $0.69(0.52-0.93)$ & $0.015^{*}$ & $0.70(0.52-0.94)$ & $0.017^{*}$ \\
\hline & & 230 & 238 & & & & \\
\hline & $\mathrm{C} / \mathrm{C}$ & $73(31.7 \%)$ & 47 (19.7\%) & 1 & & 1 & \\
\hline & $\mathrm{C} / \mathrm{T}$ & $103(44.8 \%)$ & $138(58 \%)$ & $2.08(1.33-3.25)$ & $0.001^{*}$ & $2.08(1.33-3.26)$ & $0.001^{*}$ \\
\hline & $\mathrm{T} / \mathrm{T}$ & $54(23.5 \%)$ & $53(22.3 \%)$ & $1.52(0.90-2.58)$ & 0.117 & $1.5(0.88-2.55)$ & 0.133 \\
\hline \multirow[t]{2}{*}{ Dominant } & $\mathrm{C} / \mathrm{C}$ & 73 (31.7\%) & 47 (19.7\%) & 1 & $0.003^{*}$ & 1 & $0.003^{*}$ \\
\hline & $\mathrm{C} / \mathrm{T}-\mathrm{T} / \mathrm{T}$ & 157 (68.3\%) & 191 (80.3\%) & $1.89(1.24-2.88)$ & & $1.88(1.23-2.88)$ & \\
\hline \multirow[t]{2}{*}{ Recessive } & $\mathrm{C} / \mathrm{C}-\mathrm{C} / \mathrm{T}$ & 176 (76.5\%) & 185 (77.7\%) & 1 & 0.756 & 1 & 0.699 \\
\hline & $\mathrm{T} / \mathrm{T}$ & $54(23.5 \%)$ & $53(22.3 \%)$ & $0.93(0.61-1.44)$ & & $0.92(0.60-1.42)$ & \\
\hline Log-additive & --- & --- & --- & $1.25(0.96-1.63)$ & 0.094 & $1.24(0.96-1.62)$ & 0.106 \\
\hline rs3093144 & & 229 & 238 & & & & \\
\hline \multirow[t]{3}{*}{ Co-dominant } & $\mathrm{C} / \mathrm{C}$ & $158(69 \%)$ & 175 (73.5\%) & 1 & & 1 & \\
\hline & $\mathrm{C} / \mathrm{T}$ & $61(26.6 \%)$ & $55(23.1 \%)$ & $0.81(0.53-1.24)$ & 0.341 & $0.82(0.54-1$ & 0.352 \\
\hline & $\mathrm{T} / \mathrm{T}$ & $10(4.4 \%)$ & $8(3.4 \%)$ & $0.72(0.28-1.88)$ & 0.504 & $0.74(0.28-1.92)$ & 0.533 \\
\hline \multirow[t]{2}{*}{ Dominant } & $\mathrm{C} / \mathrm{C}$ & $158(69.0 \%)$ & 175 (73.5\%) & 1 & 0.279 & 1 & 0.295 \\
\hline & $\mathrm{C} / \mathrm{T}-\mathrm{T} / \mathrm{T}$ & $71(31.0 \% \square$ & $63(26.5 \%)$ & $0.80(0.54-1.20)$ & & $0.81(0.54-1.21)$ & \\
\hline \multirow[t]{2}{*}{ Recessive } & $\mathrm{C} / \mathrm{C}-\mathrm{C} / \mathrm{T}$ & 219 (95.6\%) & 230 (96.6\%) & 1 & 0.574 & 1 & 0.604 \\
\hline & $\mathrm{T} / \mathrm{T}$ & 10 (4.4\%) & $8(3.4 \%)$ & $0.76(0.30-1.97)$ & & $0.78(0.30-2.01)$ & \\
\hline \multirow{2}{*}{$\begin{array}{l}\text { Log-additive } \\
\text { rs3093110 }\end{array}$} & --- & --- & --- & $0.83(0.59-1.16)$ & 0.273 & $0.84(0.60-1.17)$ & 0.293 \\
\hline & & 230 & 238 & & & & \\
\hline \multirow[t]{3}{*}{ Co-dominant } & $\mathrm{A} / \mathrm{A}$ & 176 (76.5\%) & 198 (83.2\%) & 1 & & 1 & \\
\hline & $\mathrm{A} / \mathrm{G}$ & 48 (20.9\%) & 37 (15.5\%) & $0.69(0.43-1.10)$ & 0.118 & $0.69(0.43-1$ & 0.132 \\
\hline & G/G & $6(2.6 \%)$ & $3(1.3 \%)$ & $0.44(0.11-1.80)$ & 0.257 & $0.44(0.11-1.78)$ & 0.250 \\
\hline \multirow[t]{2}{*}{ Dominant } & $\mathrm{A} / \mathrm{A}$ & 176 (76.5\%) & 198 (83.2\%) & 1 & 0.073 & 1 & 0.080 \\
\hline & A/G-G/G & 54 (23.5\%) & $40(16.8 \%)$ & $0.66(0.42-1.04)$ & & $0.66(0.42-1.05)$ & \\
\hline \multirow[t]{2}{*}{ Recessive } & $\mathrm{A} / \mathrm{A}-\mathrm{A} / \mathrm{G}$ & $224(97.4 \%)$ & 235 (98.7\%) & 1 & 0.299 & 1 & 0.289 \\
\hline & $\mathrm{G} / \mathrm{G}$ & $6(2.6 \%)$ & $3(1.3 \%)$ & $0.48(0.12-1.93)$ & & $0.47(0.12-1.90)$ & \\
\hline Log-additive & --- & --- & --- & $0.68(0.45-1.02)$ & 0.060 & $0.68(0.46-1.02)$ & 0.065 \\
\hline
\end{tabular}

SNP: Single nucleotide polymorphism; OR: Odds ratio; 95\% Cl: 95\% confidence interval;

$P^{\mathrm{a}}$-value calculated by logistic regression analysis; 
$P^{b}$-value calculated by logistic regression analysis with adjustments for gender and age;

${ }^{*} P$-value $<0.05$ indicates statistical significance.

Table 4: Stratified analysis of CYP4F2 polymorphisms by age and risk of HAPE 


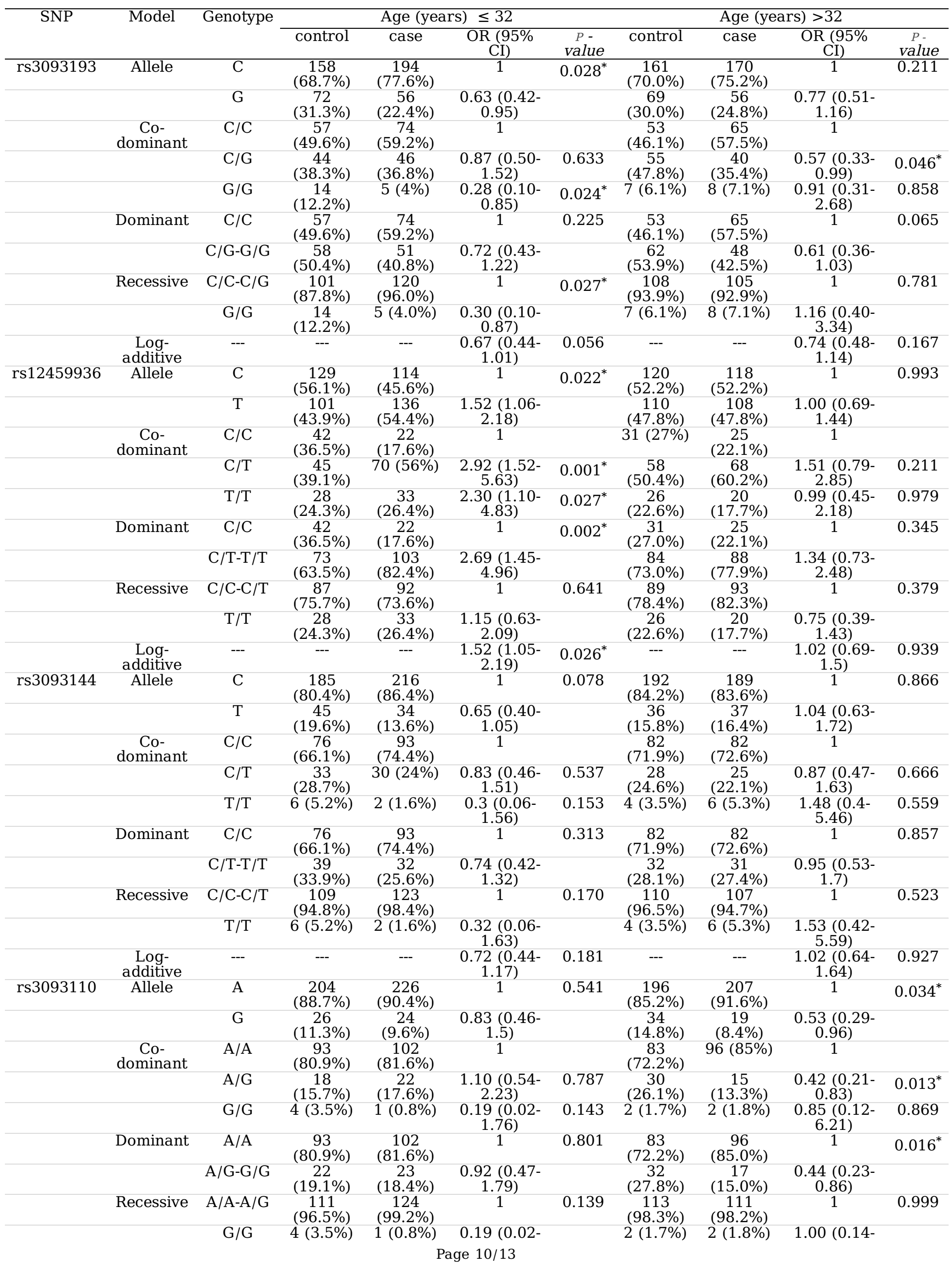


SNP: Single nucleotide polymorphism; OR: Odds ratio; 95\% Cl: 95\% confidence interval;

$P$-value calculated by logistic regression analysis with adjustments for gender and age;

${ }^{*} P$-value $<0.05$ indicates statistical significance.

Table 5. Stratified analysis of CYP4F2 polymorphisms by gender and risk of HAPE

\begin{tabular}{|c|c|c|c|c|c|c|}
\hline \multirow[t]{2}{*}{ SNP } & \multirow[t]{2}{*}{ Model } & \multirow[t]{2}{*}{ Genotype } & \multicolumn{4}{|c|}{ Male } \\
\hline & & & Control & Case & OR $(95 \% \mathrm{CI})$ & $P$ - value \\
\hline \multirow[t]{10}{*}{ rs3093193 } & Allele & $\mathrm{C}$ & $295(69.2 \%)$ & $339(77.0 \%)$ & 1 & $0.010^{*}$ \\
\hline & & $\mathrm{G}$ & $131(30.8 \%)$ & $101(23.0 \%)$ & $0.67(0.50-0.91)$ & \\
\hline & Codominant & $\mathrm{C} / \mathrm{C}$ & $101(47.4 \%)$ & $131(59.5 \%)$ & 1 & \\
\hline & & $\mathrm{C} / \mathrm{G}$ & 93 (43.7\%) & 77 (35\%) & $0.65(0.44-0.97)$ & $0.036^{*}$ \\
\hline & & $\mathrm{G} / \mathrm{G}$ & 19 (8.9\%) & $12(5.5 \%)$ & $0.48(0.22-1.04)$ & 0.062 \\
\hline & Dominant & $\mathrm{C} / \mathrm{C}$ & $101(47.4 \%)$ & $131(59.5 \%)$ & 1 & $0.015^{*}$ \\
\hline & & $\mathrm{C} / \mathrm{G}-\mathrm{G} / \mathrm{G}$ & $112(52.6 \%)$ & $89(40.5 \%)$ & $0.62(0.42-0.91)$ & \\
\hline & Recessive & $\mathrm{C} / \mathrm{C}-\mathrm{C} / \mathrm{G}$ & $194(91.1 \%)$ & $208(94.5 \%)$ & 1 & 0.147 \\
\hline & & G/G & 19 (8.9\%) & $12(5.5 \%)$ & $0.57(0.27-1.22)$ & \\
\hline & Log-additive & --- & --- & --- & $0.67(0.50-0.91)$ & $0.011^{*}$ \\
\hline \multirow[t]{10}{*}{ rs12459936 } & Allele & $\mathrm{C}$ & $233(54.7 \%)$ & $214(48.6 \%)$ & 1 & 0.074 \\
\hline & & $\mathrm{T}$ & $193(45.3 \%)$ & $226(51.4 \%)$ & $1.28(0.98-1.67)$ & \\
\hline & Co-dominant & $\mathrm{C} / \mathrm{C}$ & 68 (31.9\%) & 43 (19.5\%) & 1 & \\
\hline & & $\mathrm{C} / \mathrm{T}$ & 97 (45.5\%) & $128(58.2 \%)$ & $2.12(1.33-3.37)$ & $0.002^{*}$ \\
\hline & & $\mathrm{T} / \mathrm{T}$ & $48(22.5 \%)$ & $49(22.3 \%)$ & $1.60(0.92-2.78)$ & 0.097 \\
\hline & Dominant & $\mathrm{C} / \mathrm{C}$ & 68 (31.9\%) & $43(19.5 \%)$ & 1 & $0.003^{*}$ \\
\hline & & $\mathrm{C} / \mathrm{T}-\mathrm{T} / \mathrm{T}$ & $145(68.1 \%)$ & $177(80.5 \%)$ & $1.94(1.25-3.02)$ & \\
\hline & Recessive & $\mathrm{C} / \mathrm{C}-\mathrm{C} / \mathrm{T}$ & $165(77.5 \%)$ & $171(77.7 \%)$ & 1 & 0.885 \\
\hline & & $\mathrm{T} / \mathrm{T}$ & $48(22.5 \%)$ & $49(22.3 \%)$ & $0.97(0.61-1.52)$ & \\
\hline & Log-additive & --- & --- & --- & $1.28(0.98-1.69)$ & 0.075 \\
\hline \multirow[t]{10}{*}{ rs3093144 } & Allele & $\mathrm{C}$ & $350(82.5 \%)$ & $375(85.2 \%)$ & 1 & 0.284 \\
\hline & & $\mathrm{T}$ & 74 (17.5\%) & $65(14.8 \%)$ & $0.82(0.57-1.18)$ & \\
\hline & Co-dominant & $\mathrm{C} / \mathrm{C}$ & $146(68.9 \%)$ & $163(74.1 \%)$ & 1 & \\
\hline & & $\mathrm{C} / \mathrm{T}$ & $58(27.4 \%)$ & $49(22.3 \%)$ & $0.76(0.49-1.19)$ & 0.232 \\
\hline & & $\mathrm{T} / \mathrm{T}$ & $8(3.8 \%)$ & $8(3.6 \%)$ & $0.9(0.33-2.47)$ & 0.844 \\
\hline & Dominant & $\mathrm{C} / \mathrm{C}$ & $146(68.9 \%)$ & $163(74.1 \%)$ & 1 & 0.247 \\
\hline & & $\mathrm{C} / \mathrm{T}-\mathrm{T} / \mathrm{T}$ & $66(31.1 \%)$ & $57(25.9 \%)$ & $0.78(0.51-1.19)$ & \\
\hline & Recessive & $\mathrm{C} / \mathrm{C}-\mathrm{C} / \mathrm{T}$ & $204(96.2 \%)$ & $212(96.4 \%)$ & 1 & 0.951 \\
\hline & & $\mathrm{T} / \mathrm{T}$ & $8(3.8 \%)$ & $8(3.6 \%)$ & $0.97(0.36-2.63)$ & \\
\hline & Log-additive & --- & --- & --- & $0.84(0.59-1.19)$ & 0.324 \\
\hline \multirow[t]{10}{*}{ rs3093110 } & Allele & A & $369(86.6 \%)$ & $402(91.4 \%)$ & 1 & $0.026^{*}$ \\
\hline & & $\mathrm{G}$ & $57(13.4 \%)$ & 38 (8.6\%) & $0.61(0.40-0.94)$ & \\
\hline & Co-dominant & $\mathrm{A} / \mathrm{A}$ & $162(76.1 \%)$ & $184(83.6 \%)$ & 1 & \\
\hline & & $\mathrm{A} / \mathrm{G}$ & $45(21.1 \%)$ & 34 (15.5\%) & $0.67(0.41-1.11)$ & 0.119 \\
\hline & & $\mathrm{G} / \mathrm{G}$ & $6(2.8 \%)$ & $2(0.9 \%)$ & $0.28(0.06-1.41)$ & 0.123 \\
\hline & Dominant & $\mathrm{A} / \mathrm{A}$ & $162(76.1 \%)$ & $184(83.6 \%)$ & 1 & 0.055 \\
\hline & & A/G-G/G & $51(23.9 \%)$ & 36 (16.4\%) & $0.63(0.39-1.01)$ & \\
\hline & Recessive & $\mathrm{A} / \mathrm{A}-\mathrm{A} / \mathrm{G}$ & $207(97.2 \%)$ & $218(99.1 \%)$ & 1 & 0.145 \\
\hline & & $\mathrm{G} / \mathrm{G}$ & $6(2.8 \%)$ & $2(0.9 \%)$ & $0.3(0.06-1.51)$ & \\
\hline & Log-additive & --- & --- & --- & $0.63(0.41-0.96)$ & $0.034^{*}$ \\
\hline
\end{tabular}

SNP: Single nucleotide polymorphism; OR: Odds ratio; 95\% Cl: 95\% confidence interval;

$P$-value calculated by logistic regression analysis with adjustments for gender and age;

${ }^{*} P$-value $<0.05$ indicates statistical significance.

Table 6. Four SNPs in CYP4F2 haplotypes and their associations with HAPE risk in stratified analysis 


\begin{tabular}{|c|c|c|c|c|c|c|c|c|}
\hline \multirow[t]{2}{*}{ Stratification } & \multirow[t]{2}{*}{ SNP } & \multirow[t]{2}{*}{ Haplotype } & \multirow{2}{*}{$\begin{array}{c}\text { Freq } \\
\text { (Case) }\end{array}$} & \multirow{2}{*}{$\begin{array}{c}\text { Freq } \\
\text { (Control) }\end{array}$} & \multicolumn{2}{|c|}{$\begin{array}{c}\text { Without } \\
\text { adjusted }\end{array}$} & \multicolumn{2}{|c|}{ With adjusted } \\
\hline & & & & & $\begin{array}{l}\text { adjl } \\
\text { OR } \\
\text { (95\% } \\
\text { CI) }\end{array}$ & $\begin{array}{c}\text { isted } \\
P^{\mathrm{a}}- \\
\text { value }\end{array}$ & $\begin{array}{c}\mathrm{OR} \\
(95 \% \\
\mathrm{CI})\end{array}$ & $\begin{array}{c}P^{\mathrm{b}}- \\
\text { value }\end{array}$ \\
\hline \multirow[t]{4}{*}{ Male } & rs3093193|rs12459936|rs3093144|rs3093110 & GCCG & 0.868 & 0.804 & $\begin{array}{c}1.58 \\
(1.03- \\
2.44)\end{array}$ & $0.038^{*}$ & $\begin{array}{c}1.57 \\
(1.02- \\
2.43)\end{array}$ & $0.040^{*}$ \\
\hline & & GCTA & 0.544 & 0.439 & $\begin{array}{l}1.22 \\
(0.86- \\
1.74)\end{array}$ & 0.273 & $\begin{array}{l}1.21 \\
(0.85- \\
1.73)\end{array}$ & 0.289 \\
\hline & & CTCA & 0.908 & 0.883 & $\begin{array}{c}1.30 \\
(0.99- \\
1.72)\end{array}$ & 0.059 & $\begin{array}{c}1.30 \\
(0.99- \\
1.71)\end{array}$ & 0.064 \\
\hline & & CCCA & 0.228 & 0.248 & $\begin{array}{l}1.08 \\
(0.78- \\
1.48)\end{array}$ & 0.653 & $\begin{array}{l}1.08 \\
(0.78- \\
1.48)\end{array}$ & 0.654 \\
\hline \multirow[t]{4}{*}{ Age $\leq 32$} & rs3093193|rs12459936|rs3093144 & GCT & 0.868 & 0.804 & $\begin{array}{c}1.40) \\
1.57 \\
(0.97- \\
2.54)\end{array}$ & 0.068 & $\begin{array}{l}1.44 \\
(0.88- \\
2.36)\end{array}$ & 0.145 \\
\hline & & CTC & 0.544 & 0.439 & $\begin{array}{l}1.50 \\
(1.05- \\
2.15)\end{array}$ & $0.025^{*}$ & $\begin{array}{l}1.52 \\
(1.05- \\
2.19)\end{array}$ & $0.026^{*}$ \\
\hline & & GCC & 0.908 & 0.883 & $\begin{array}{l}1.28 \\
(0.73- \\
2.24)\end{array}$ & 0.389 & $\begin{array}{l}1.33 \\
(0.75- \\
2.36)\end{array}$ & 0.327 \\
\hline & & CCC & 0.228 & 0.248 & $\begin{array}{c}2 . .44) \\
0.90 \\
(0.60- \\
1.36)\end{array}$ & 0.620 & $\begin{array}{c}2.56) \\
0.85 \\
(0.56- \\
1.31)\end{array}$ & 0.470 \\
\hline
\end{tabular}

Block comprised of the three closely linked SNPs rs9440302 and rs1198574;

OR: odds ratio, $95 \% \mathrm{Cl}$ : $95 \%$ confidence interval;

$P^{a}$-value calculated by Wald test;

$P^{b}$-value calculated by Wald test and adjusted by gender and age;

${ }^{*} P$-value $<0.05$ indicates statistical significance.

Figures 


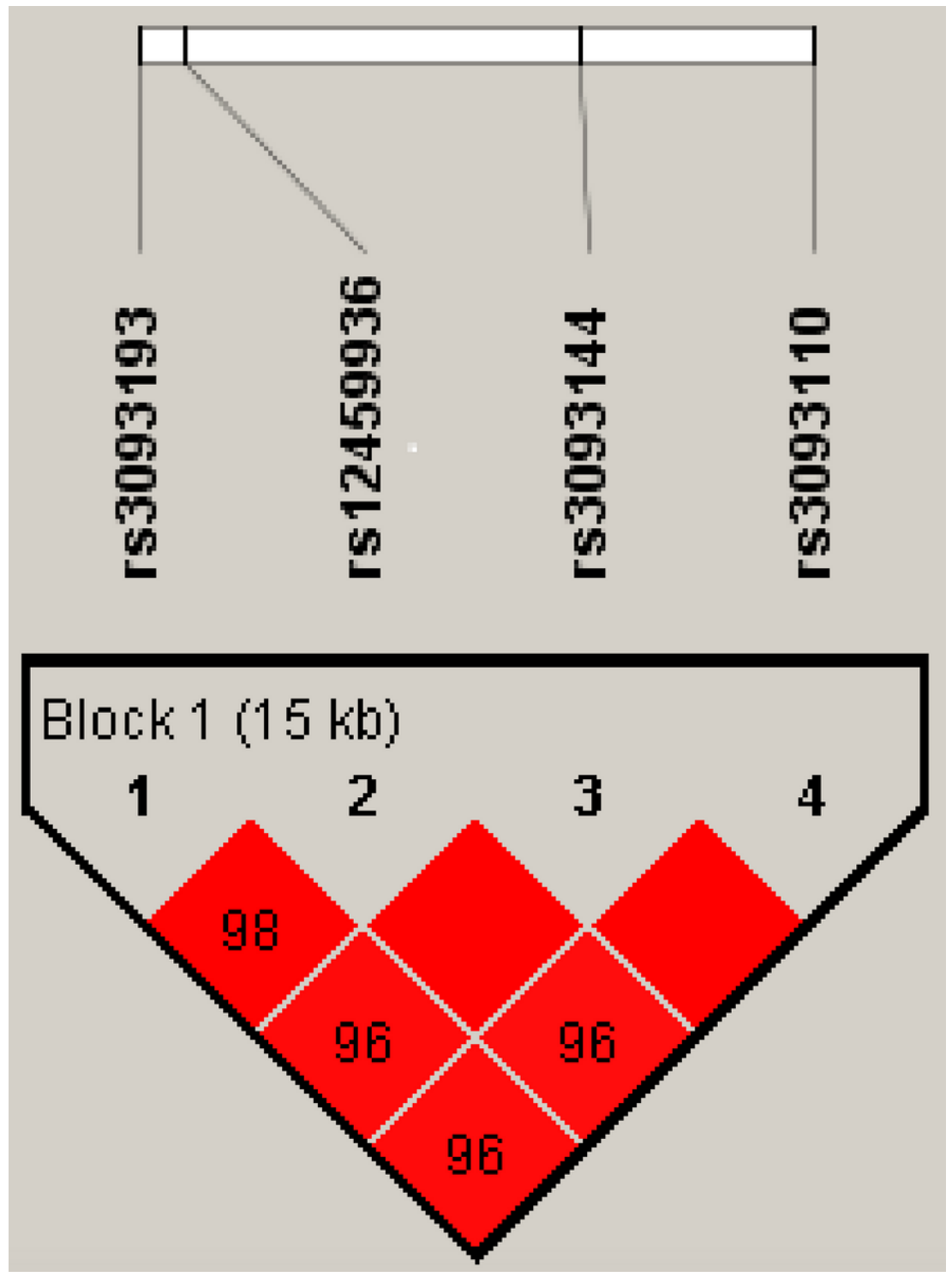

\section{Figure 1}

Haplotype block map for three SNPs in the CYP4F2 gene ( $\left.D^{\prime}\right)$. Linkage disequilibrium analysis of CYP4F2 in individuals at age $\leq 32$ years. LD is indicated using standard color schemes with bright red signifying very strong $L D\left(r 2<1 / D^{\prime}=1\right)$, pink red $\left(D^{\prime}<1\right)$.

\section{Supplementary Files}

This is a list of supplementary files associated with this preprint. Click to download.

- SupplementaryTables.docx 